\title{
ENGINEERING SEISMOLOGY
}

\author{
W. R. Stephenson*
}

\section{Instrumental effects}

The artershock that occurred at 12:45 GiT on June 5 gatve the first direct comparison of a 3component time base accelerograph (M01) with the simpler scratchplate horizontal accelerograph (SP 1) developed at Physics and Engineering Laboratory. Figure 1 shows both the sP1 record, and its equivalent derived from the MO1 at lestport post Office. The scratch-jlate type of instrument

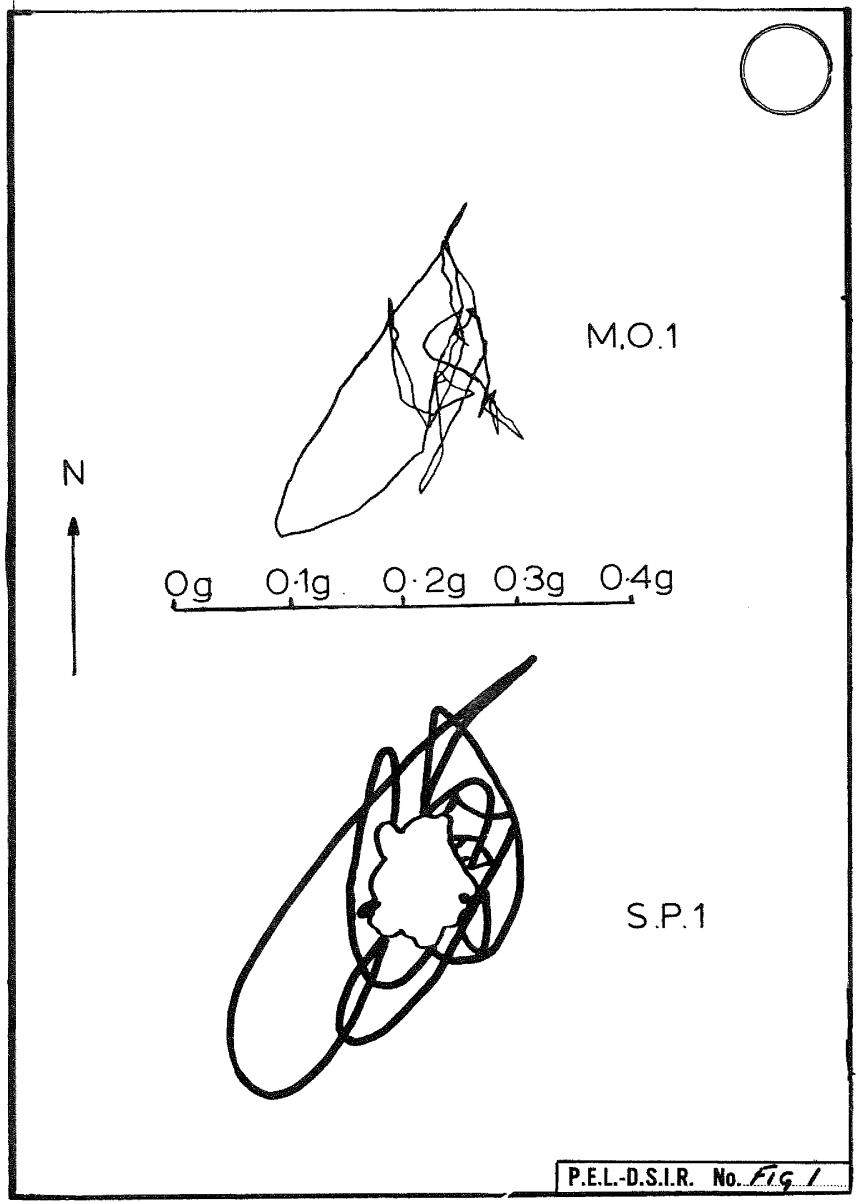

gives a food iclea of tlle number and direction of impulses, but only an approximate idea of their magnitude。
The largest five aftershocks recorded on the ilo 1 proved to have their peal energy concentrated near $7 \mathrm{c} / \mathrm{s}$ which is nearer to structural and instrumental resoninces than the $4-5 \mathrm{c} / \mathrm{s}$ thought typical before.

We can say that accelerations of the order of $0.3 \mathrm{~g}$ to $0.5 \mathrm{~g}$ occurred at close in areas such as lurchison, Reefton, and Vestport。 In any event, present thinking indicates that microzoning effects could dominate, and that peak accelerations at a point are no more than an indication of the order of forces in an area.

The SP1 record made at the Greymouth Post Office shows a pronounced east-west elongation, not characteristic of the earthquake in other localities. The elongation could be attributed to local ground effects.

\section{Structural and ground effects}

it Inangahua, an, attempt was made to deduce ground motion from natural objects. For example, stones that have been thrown from depressions have been taken to indicate a vertical acceleration of greater than $1 \mathrm{~g}$ o Permanent displacements of objects can be taken to imply the directions of accelerations. Care must be taken in doing this sort of work, as structural effects can easily dominate. The direction of attack must be shown by many structures before it becomes admissable evidence. On this basis nothing was found at Inangahua.

+ Physics and Engineering Laboratory, Department of Scientific and Industrial Research.

This paper was published in the D.S.I.R. Bulletin No. 193 
The most significant damage at Inangahua was that occurring to the Inangahua road-rail bxidge, the Bullex rail bridge, and domestic dwelings.

The Inangahua bridge (rig。2) and the Bullex bridge (Ifigs. 3 and 4) were attacked in two distinct ways.

Each pier, with some of the mass of the spans, acted in cantilever fashion, with the excitation applied at the top. In this situation, the maximum bending momerit occurs near the root, and, indeed, the piexs on both bxidges were fractured near the ground. Such a damaged cantilever can still withstand comsiderable vertical loading.

Both the bxidges also suffexed damage due to longltudinal compressive forces, which sheared bolts holding the spans to plers and abutments, closed expension joints in the rails, and buckled vaxious straps. These longltudinal forces were apparentiy caused by soll flowing behind the abutments and forcing them towards the river, duxing times when the abutments were vibrated in that dilection. This compressive force was a blessing In disguise, because the inertial foxces developed werelnsufflcientto detach the spans from the plers, and allow the spans to fall into the river. The compressive forces gave the structure enough coherence to remain on the piexs, and the total damage was smaller than it may have been. The action of spans detaching from piers was seen on the showa bridge, Niligata, Japan after the earthqualse of June 16, 1964.

Domestic dwellings suffered, as usual, from certain weaknesses in structural design. The New Zealand wood-frame dwelling would be highly resistant to earthqualkes if it had continuous foundations extermally, and a light reinforced chimney. Conventional piles have low resistance to a force applied horizontally at their tops, while the chimey is fax stiffer than the building fxame and, In undergoing displacement relative to the frame, causes damege. The present inadequacy of tie wires and tile battens was also demonstrated, and many examples of fallure of each were seen. Even when the roof did not shed the tilles, the chinmey crashed through, but corrugatediron roofs deflected the chimeys to the ground outside.

\section{Conclusion}

Because there wexe no major engineexing vorls, or multstorey buildings in the area, the main lessons for engineering seismology were Indirect. The low casualties and relatively low damage may lead to the severity of this earthquake being under-rated. 


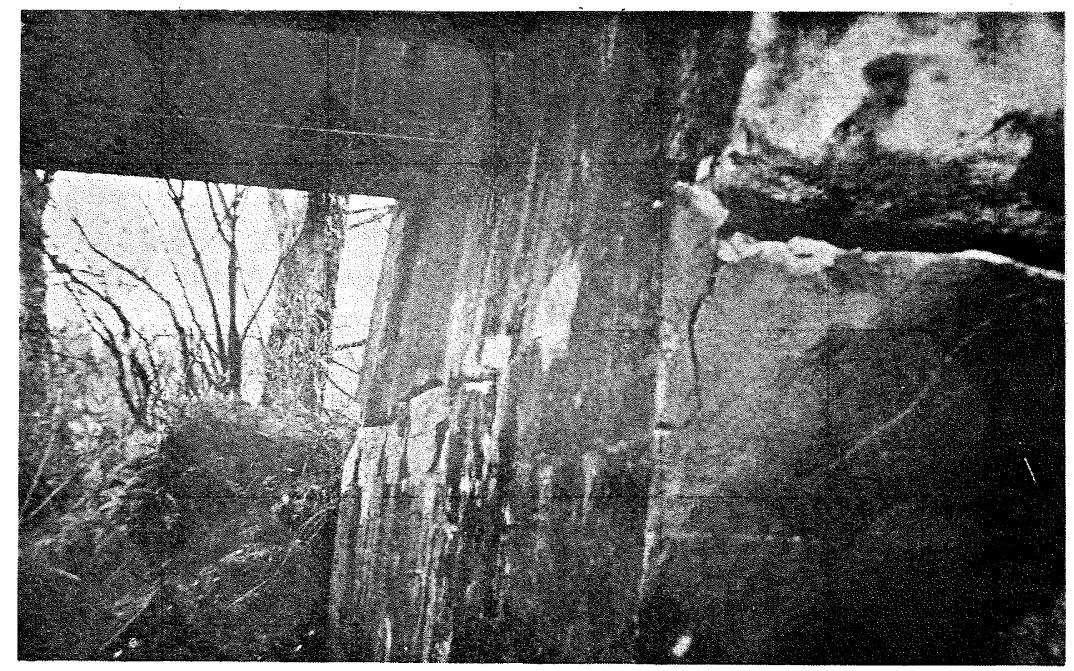

Fig. 2 Reefton buttress of the Inangahua roadrail bridge, looking upstream. Soil has thrust the buttress towards the river, causing the fracture shown.

Fig. 3 Northernmost pier of the Buller rail bridge, showing a typical fracture near ground level.
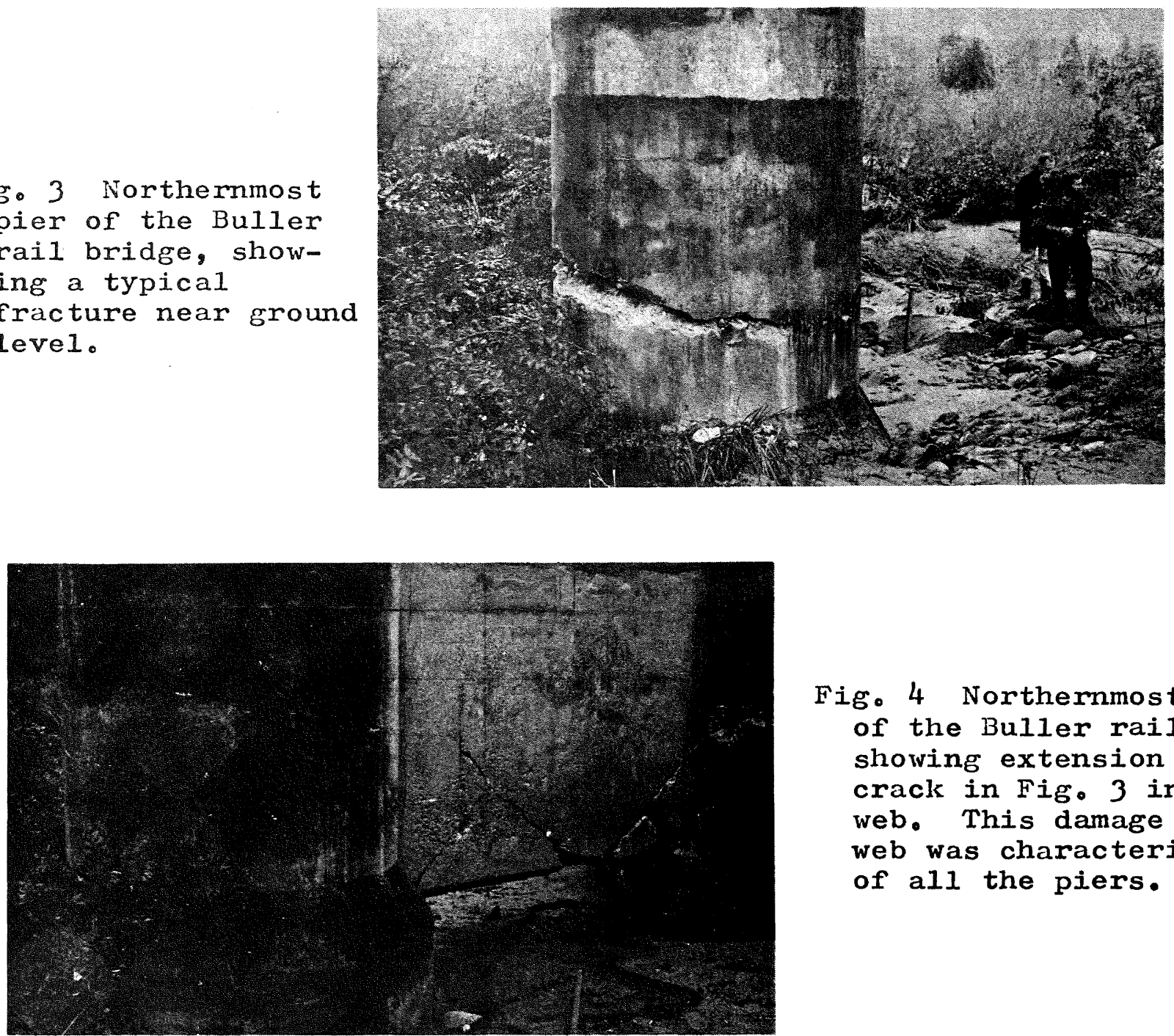

Fig. 4 Northernmost pier of the Buller rail bridge showing extension of the crack in Fig. 3 into the web. This damage to the web was characteristic of all the piers. 